\title{
Molecular Identification of Cryptosporidium Species from Pet Snakes in Thailand
}

\author{
Benjarat Yimming1, Khampee Pattanatanang', Pornchai Sanyathitiseree ${ }^{2}$, Tawin Inpankaew1, \\ Ketsarin Kamyingkird', Nongnuch Pinyopanuwat ${ }^{1}$, Wissanuwat Chimnoi', Jumnongjit Phasuk ${ }^{1, *}$ \\ 'Department of Parasitology, Faculty of Veterinary Medicine, Kasetsart University, Bangkok 10900, Thailand; ${ }^{2}$ Department of Large Animal and \\ Wildlife Clinical Science, Faculty of Veterinary Medicine, Kasetsart University, Nakhon Pathom 73140, Thailand
}

\begin{abstract}
Cryptosporidium is an important pathogen causing gastrointestinal disease in snakes and is distributed worldwide. The main objectives of this study were to detect and identify Cryptosporidium species in captive snakes from exotic pet shops and snake farms in Thailand. In total, 165 fecal samples were examined from 8 snake species, boa constrictor (Boa constrictor constrictor), corn snake (Elaphe guttata), ball python (Python regius), milk snake (Lampropeltis triangulum), king snake (Lampropeltis getula), rock python (Python sebae), rainbow boa (Epicrates cenchria), and carpet python (Morelia spilota). Cryptosporidium oocysts were examined using the dimethyl sulfoxide (DMSO)-modified acid-fast staining and a molecular method based on nested-PCR, PCR-RFLP analysis, and sequencing amplification of the SSU rRNA gene. DMSO-modified acid-fast staining revealed the presence of Cryptosporidium oocysts in 12 out of 165 (7.3\%) samples, whereas PCR produced positive results in 40 (24.2\%) samples. Molecular characterization indicated the presence of Cryptosporidium parvum (mouse genotype) as the most common species in 24 samples (60\%) from 5 species of snake followed by Cryptosporidium serpentis in 9 samples (22.5\%) from 2 species of snake and Cryptosporidium muris in 3 samples $(7.5 \%)$ from $P$. regius.
\end{abstract}

Key words: Cryptosporidium parvum, Cryptosporidium serpentis, Cryptosporidium muris, snake, nested PCR, SSU rRNA, Thailand

\section{INTRODUCTION}

Cryptosporidium spp. are apicomplexan protozoan parasites that infect a wide variety of vertebrate hosts, including reptiles, birds, fish, amphibians, and mammals, and cause cryptosporidiosis [1]. Cryptosporidiosis is characterized by acute gastrointestinal disturbances, mucoid or hemorrhagic watery diarrhea, fever, lethargy, anorexia, and death in humans and mammals [2]. Cryptosporidium infections have been described in at least 57 reptilian species consisting of 40 species of snakes, 15 species of lizards, and 2 species of tortoises [3]. Unlike in other animals in which infection with Cryptosporidium spp. is usually self-limiting in immunocompetent individuals, cryptosporidiosis in reptiles is frequently chronic and sometimes lethal in snakes [4]. Two species, Cryptosporidium serpentis and Cryptosporidium varanii (syn. C. saurophilum) have been described in

\footnotetext{
- Received 12 October 2015, revised 28 April 2016, accepted 6 May 2016.

*Corresponding author (fvetjjp@ku.ac.th)

(C) 2016, Korean Society for Parasitology and Tropical Medicine

This is an Open Access article distributed under the terms of the Creative Commons Attribution Non-Commercial License (http://creativecommons.org/licenses/by-nc/4.0) which permits unrestricted non-commercial use, distribution, and reproduction in any medium, provided the original work is properly cited.
}

snakes and lizards to date $[4,5]$. C. serpentis is an important parasite in snakes and is usually found in the gastric epithelium [6]. Clinical signs of cryptosporidiosis in snakes have been described as anorexia, lethargy, postprandial regurgitation, midbody swelling, and weight loss [1]. The infection occurs more frequently in adults rather than in young reptiles, unlike in mammals and birds [7]. While C. varanii was originally described in lizards as causing weight loss, abdominal swelling and mortality, it can be found in snakes but has no significant signs [5].

Stressed animals, which have been raised in a limited living space together with various types of species, are more likely to contribute to the spread of the parasite [8]. The above factors have been reported to suppress the immune responses and increase the opportunity for pathogens to cause infections and consequently spread to other animals including humans $[8,9]$. Cryptosporidium infection in snakes is difficult to identify, especially in those with a subclinical infection [10]. Conventional methods for detection of Cryptosporidium oocysts (including microscopic examination of fecal smears with acid-fast stains) are not capable of identification to the species level. Therefore, molecular techniques have been developed to detect and dif- 
ferentiate Cryptosporidium at the species/genotype and subtype levels [11]. Previously, molecular analysis of Cryptosporidium infection in snakes has identified C. parvum, C. muris, and Cryptosporidium mouse genotype, which probably originated from the ingestion of infected rodents or other prey $[4,6,12$ 14]. Likewise, molecular techniques will help ensure accurate species identification of Cryptosporidium oocysts in snakes.

The pet snake business has become popular in Thailand. However, there is a lack of information regarding Cryptosporidium infection in snakes in Thailand. The present study aimed to identify Cryptosporidium species in captive snake fecal samples using microscopic and molecular examinations. This study will be relevant to disease surveillance and to the improvement of the management of aliments in captive snakes in Thailand.

\section{MATERIALS AND METHODS}

\section{Sample collection}

In total, 165 fecal samples were collected from asymptomatic snakes of 8 species in 6 genera (Table 1). Of these, 34 snakes were housed in 5 exotic pet shops, and 131 were from 2 snake farms. Fecal samples were stored at $4^{\circ} \mathrm{C}$ before analysis.

\section{Microscopy}

Cryptosporidium oocysts were concentrated using Sheather's sugar flotation technique [15]. One drop from the top of the supernatant was smeared on a slide followed by staining using DMSO-modified acid-fast stain as previously described [16].

\section{DNA extraction}

DNA was extracted from the supernatant produced using Sheather's sugar flotation technique with a commercial kit (E.Z.N.A. ${ }^{\circledR}$ Stool DNA Kit, Omega Biotek Inc., Norcross, GA, USA) following the manufacturer's protocol. DNA was stored at $-20^{\circ} \mathrm{C}$ before molecular analysis.

\section{Nested PCR amplification and PCR- RFLP analysis}

Amplification of the 819-825 bp polymorphic fragment of the SSU rRNA using nested PCR was performed as previously described [17]. Briefly, the PCR conditions were composed of pre-denaturation at $94^{\circ} \mathrm{C}$ for $5 \mathrm{~min}$, then 35 cycles of denaturation at $94^{\circ} \mathrm{C}$ for $45 \mathrm{sec}$, annealing at $55^{\circ} \mathrm{C}$ for $45 \mathrm{sec}$, and extension at $72^{\circ} \mathrm{C}$ for $1 \mathrm{~min}$, followed by final extension at $72^{\circ} \mathrm{C}$ for $10 \mathrm{~min}$. RFLP of the secondary PCR products of $C$. parrum positive samples was performed using Vsp I (Thermo Fisher Scientific Inc., Rochester, New York, USA) for the genotyping of C. parrum [17]. The reaction mixture contained $0.5 \mu \mathrm{l}$ of Vsp

Table 1. Detection of Cryptosporidium in snakes using microscopic and molecular methods

\begin{tabular}{|c|c|c|c|c|c|c|c|c|c|}
\hline \multirow{3}{*}{ Scientific name } & \multirow{3}{*}{ Common name } & \multirow{2}{*}{\multicolumn{2}{|c|}{ No. of samples }} & \multicolumn{4}{|c|}{ No. of positive samples } & \multicolumn{2}{|c|}{ Species and/or genotype (no. of samples) } \\
\hline & & & & \multicolumn{2}{|c|}{ Acid fast stain } & \multicolumn{2}{|c|}{ PCR } & \multirow{2}{*}{ Sequence analysis } & \multirow{2}{*}{ RFLP } \\
\hline & & Farm & Pet shop & Farm & Pet shop & Farm & Pet shop & & \\
\hline \multirow[t]{2}{*}{$\begin{array}{l}\text { Boa constrictor } \\
\text { constrictor }\end{array}$} & Boa constrictor & 14 & 3 & 0 & 0 & 4 & 1 & C. parvum (4) & C. parvum mouse genotype \\
\hline & & & & & & & & $\begin{array}{l}\text { Cryptosporidium } \\
\text { mouse genotype (1) }\end{array}$ & - \\
\hline \multirow[t]{3}{*}{ Elaphe guttata } & Corn snake & 71 & 5 & 7 & 2 & 17 & 2 & C. parvum (10) & C. parvum mouse genotype \\
\hline & & & & & & & & C. serpentis (8) & - \\
\hline & & & & & & & & C. saurophilum (1) & - \\
\hline Epicrates cenchria & Rainbow boa & 0 & 1 & 0 & 0 & 0 & 0 & - & - \\
\hline Lampropeltis getula & King snake & 19 & 2 & 0 & 0 & 1 & 0 & C. serpentis (1) & - \\
\hline $\begin{array}{l}\text { Lampropeltis } \\
\text { triangulum }\end{array}$ & Milk snake & 4 & 3 & 0 & 0 & 1 & 1 & C. parvum (2) & C. parvum mouse genotype \\
\hline \multirow[t]{2}{*}{ Morelia spilota } & Carpet python & 0 & 4 & 0 & 1 & 0 & 4 & C. parvum (3) & C. parvum mouse genotype \\
\hline & & & & & & & & C. andersoni (1) & - \\
\hline \multirow[t]{3}{*}{ Python regius } & Ball python & 23 & 15 & 2 & 0 & 0 & 9 & C. parvum (5) & C. parvum mouse genotype \\
\hline & & & & & & & & C. muris (3) & - \\
\hline & & & & & & & & $\begin{array}{l}\text { Cryptosporidium } \\
\text { mouse genotype (1) }\end{array}$ & - \\
\hline Python sebae & Rock python & 0 & 1 & 0 & 0 & 0 & 0 & - & - \\
\hline Total & & 131 & 34 & 9 & 3 & 23 & 17 & & \\
\hline
\end{tabular}


I (Thermo Fisher Scientific Inc.), $2.2 \mu \mathrm{l}$ of restriction buffer, and $5 \mu \mathrm{l}$ of PCR product at $37^{\circ} \mathrm{C}$ for $30 \mathrm{~min}$, under conditions recommended by the manufacturer. The digested products were analyzed using $2 \%$ agarose gel electrophoresis.

\section{DNA sequencing and phylogenetic analysis}

The positive Cryptosporidium samples were submitted for sequencing (1st Base Laboratory, Selangor, Malaysia). The DNA sequences were compared with those in the GenBank database using the basic local alignment search tool (BLAST) algorithm, and the species of Cryptosporidium present in the sample was determined. The nucleotide sequences of the partial SSU rRNA gene of the Cryptosporidium parasites were deposited in the GenBank $^{\mathrm{TM}}$ database under the accession nos. KM870564 KM870603. Multiple alignments were done using the ClustalW program [18,19]. A neighbor-joining tree was constructed from the aligned sequences using the MEGA version 5 software [20].

\section{Statistical analysis}

Statistical analysis was performed using a chi-square $\left(\chi^{2}\right)$ test in the Number Cruncher Statistical System (NCSS) version 2000 to determine the association between the prevalence of Cryptosporidium infection vs host genders and host locations. Values were tested for significance at $P \leq 0.05$.

\section{RESULTS}

Of the 165 fecal samples from captive snakes, 12 (7.3\%) were detected as positive for Cryptosporidium oocysts using the DMSO-modified acid-fast stain, and 40 (24.2\%) were positive using nested PCR (Table 1). Seventeen out of 34 samples (50.0\%) from pet shops and 23 out of 131 samples (17.6\%) from private farms were positive for Cryptosporidium. Among the positive results from nested PCR testing, sequencing analysis identified 24 (60.0\%); 9 (22.5\%); 3 (7.5\%), 2 (5.0\%), 1
(2.5\%), and 1 (2.5\%) as C. parrum, C. serpentis, C. muris, Cryptosporidium mouse genotype, C. andersoni, and C. saurophilum, respectively (Table 1). C. parvum was detected from Boa constrictor constrictor (4), Elaphe guttata (10), Lampropeltis triangulum (2), Python regius (5), and Morelia spilota (3). C. serpentis was detected from Lampropeltis getula (1) and Elaphe guttata (8). C. muris was detected from Python regius. Cryptosporidium mouse genotype was detected from B. constrictor constrictor (1) and $P$. regius. C. andersoni was detected from M. spilota. C. saurophilum was detected from E. guttata (Table 1).

Sequencing analysis indicated that $C$. parrum, $C$. serpentis, $C$. muris, Cryptosporidium mouse genotype, C. andersoni, and C. saurophilum were 99\% identical to GenBank accession nos. DQ898158, AF093499, EU553588, EU553589, JX515549, and EU553551, respectively. Differentiation of the C. parnum genotype by PCR-RFLP showed that all 24 C. parnum positive samples were C. parrum mouse genotype (Fig. 1). This genotype is

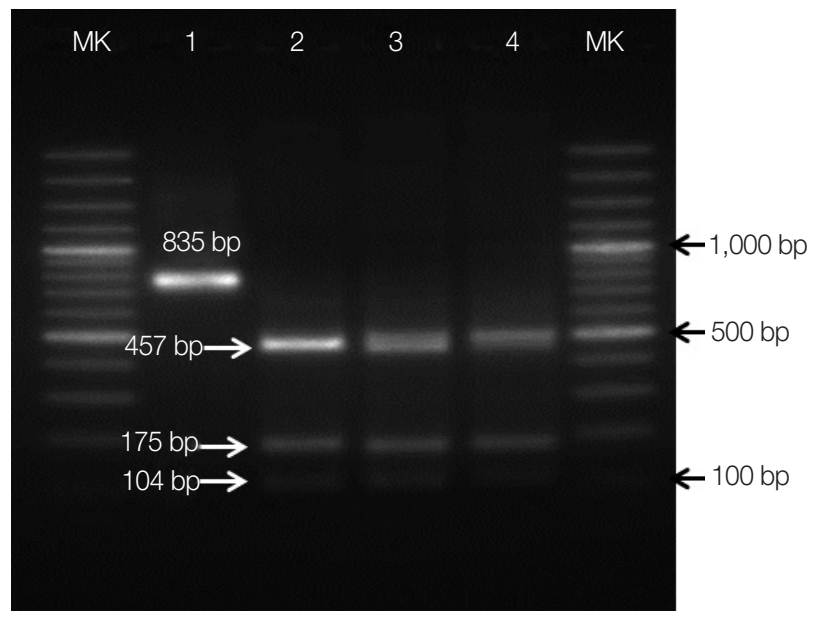

Fig. 1. PCR-RFLP analysis. Lane 1 is Cryptosporidium parvum without digestion showing a single 835 bp band and lanes 2-4 are C. parvum "mouse genotype" showing digested bands of 104, 175, and $457 \mathrm{bp}$. The molecular weight marker size, $100 \mathrm{bp}$ ladder. Black arrow, the DNA marker size at $100 \mathrm{bp}, 500 \mathrm{bp}$, and $1,000 \mathrm{bp}$.

Table 2. Risk factors associated with Cryptosporidium spp. infection in snakes

\begin{tabular}{|c|c|c|c|c|c|}
\hline Variable & No. (\%) of infected snakes & No. (\%) of non-infected snakes & Total sample & $\chi^{2}$ & $P$-value ${ }^{a}$ \\
\hline $\begin{array}{l}\text { Sex }^{b} \\
\text { Male } \\
\text { Female }\end{array}$ & $\begin{array}{r}25(17.4) \\
6(12.8) \\
19(19.6)\end{array}$ & $\begin{array}{r}119(82.6) \\
41(87.2) \\
78(80.4)\end{array}$ & $\begin{array}{r}144 \\
47 \\
97\end{array}$ & $1.027 \mathrm{df}=1$ & 0.310 \\
\hline $\begin{array}{l}\text { Location } \\
\text { Pet shops } \\
\text { Farms }\end{array}$ & $\begin{array}{l}40(24.2) \\
17(50.0) \\
23(17.6)\end{array}$ & $\begin{array}{r}125(75.8) \\
17(50.0) \\
108(82.4)\end{array}$ & $\begin{array}{r}165 \\
34 \\
131\end{array}$ & $15.470 \mathrm{df}=1$ & 0.00008 \\
\hline
\end{tabular}

a $P \leq 0.05$ was considered statistically significant.

${ }^{b}$ Gender data were missing in 21 samples. 


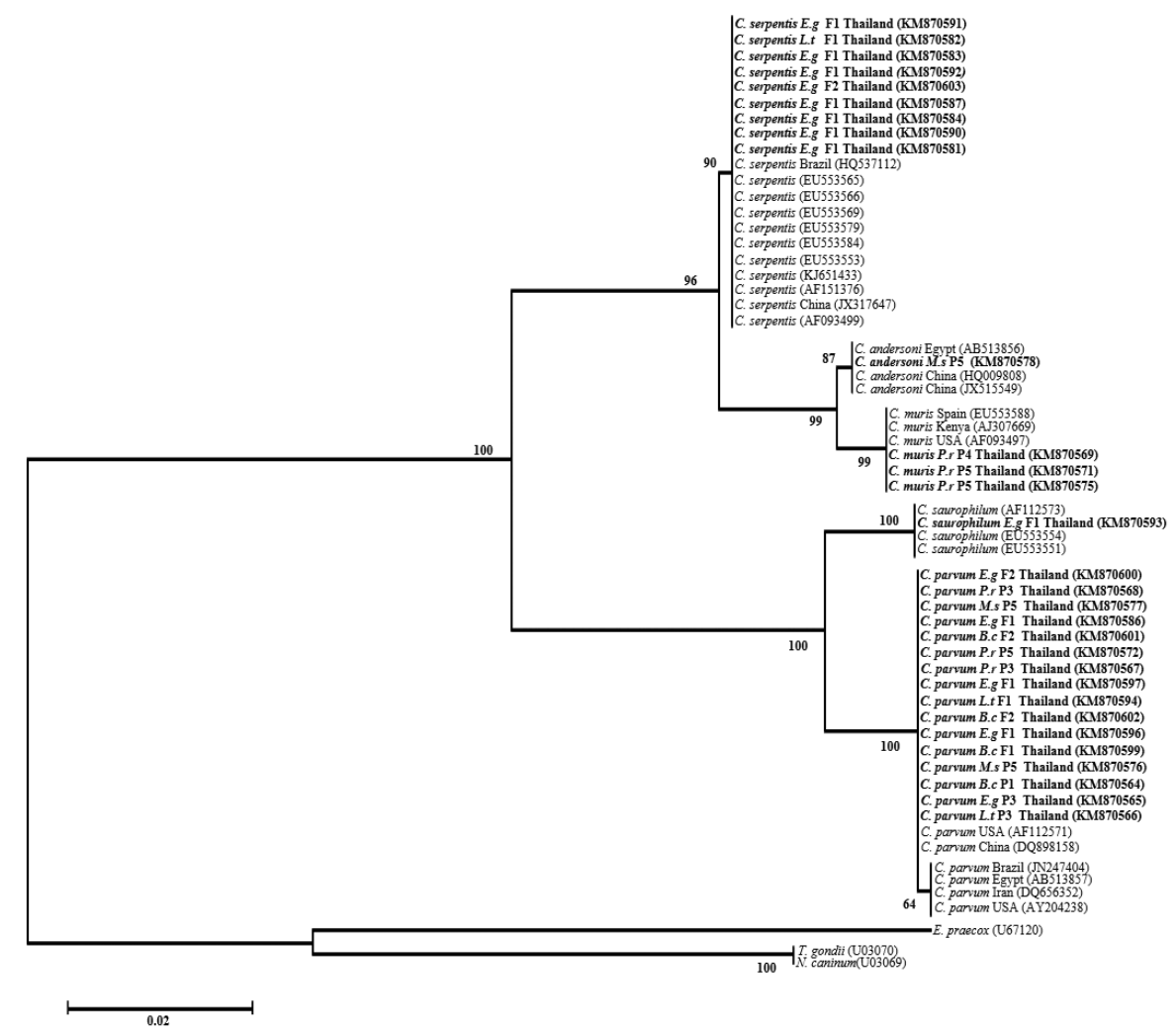

Fig. 2. Phylogenetic relationships among Cryptosporidium species found in this study and other Cryptosporidium spp. performed using neighbor-joining analysis of the SSU rDNA fragment. The samples with local origin "Thailand" were in current study. Captive snake: $B$. $c=$ Boa constrictor constrictor, E.g =Elaphe guttata, L.t=Lampropeltis triangulum, M.s=Morelia spilota, P.r=Python regius. Location: P1 = Pet shop, P2=Pet shop, P4 = Pet shop 4, P5= Pet shop 5, F1 = Farm 1, F2= Farm 2.

considered as nonpathogenic in snakes [21].

Risk factor analysis showed that there were infection rates of $12.8 \%$ and $19.6 \%$ of Cryptosporidium spp. in male and female snakes $\left(\chi^{2}=1.027, P=0.310\right)$, respectively, and the infection rates were $50.0 \%$ and $17.6 \%$ on pet shops and farms $\left(\chi^{2}=\right.$ $17.470, P=0.00008)$, respectively. These results indicated that location was a statistically significant factor associated with Cryptosporidium spp. infection in snakes (Table 2). The neighbor-joining analysis results showed that 2 distinctive clades of intestinal and stomach Cryptosporidium species from this study were clearly separated (Fig. 2). Intestinal Cryptosporidium species consisted of C. parvum, Cryptosporidium mouse genotype, and C. saurophilum, while stomach Cryptosporidium species consisted of C. serpentis, C. muris, and C. andersoni.

\section{DISCUSSION}

Cryptosporidiosis is a well-known cause of chronic hypertrophic gastritis, and is possibly lethal in captive snakes [5,22].
The present study was the first identification of Cryptosporidium infection in pet snakes in Thailand. We found $7.3 \%$ of the Cryptosporidium oocysts using the acid-fast stain technique and $24.2 \%$ of the Cryptosporidium DNA using a molecular method. The acid-fast staining technique is less sensitive for the detection of Cryptosporidium infection. However, it is the easiest and most effective method for veterinary clinical diagnosis [23]. Moreover, PCR is a sensitive and specific detection technique, which resulted in a much higher proportion of Cryptosporidium positive samples in comparison to acid-fast staining [24]. Additionally, PCR is an important method for the identification of Cryptosporidium species or genotypes in samples with low numbers of oocysts $[25,26]$. Thus, PCR is still hindered by its high cost and time-consuming DNA extraction, PCR amplification, and gel electrophoresis $[27,28]$. A combination of several diagnostic techniques for the detection of Cryptosporidium oocysts is still needed [29].

In the present study, sequencing analysis of the 18S rRNA gene revealed the presence of $C$. serpentis in the corn snake ( $E$. 
guttata) and king snake (L. getula). These findings were similar to previous studies, which have found that $C$. serpentis is most common in snakes $[4,6,9,12,14,30]$. Additionally, we found $C$. saurophilum in the corn snake (E. guttata), which is similar to previous reports $[4-6,13]$. C. saurophilum was originally described as an intestinal parasite mainly in lizards [31]. The presence of $C$. saurophilum in reptiles other than lizards might have resulted from the fact that they were housed together [45]. Moreover, none of the infected animals showed any clinical signs of the disease in the present study, which was in agreement with previous reports [6,9]. However, the subclinical stage can last for years in these animals [32].

We have confirmed the presence of C. parnum, C. muris, and C. andersoni in captive snakes. C. parvum and C. muris were considered as Cryptosporidium from mammals. Therefore, they were not pathogenic in snakes $[33,34]$. On the other hand, we have also confirmed $C$. andersoni in captive snakes. Interestingly, C. andersoni was commonly found in infected cattle abomasum. Possibly, the finding of other Cryptospodium genotypes in snakes might be due to infection from infected prey animals [35]. This is the first report of $C$. andersoni in captive snakes.

The study of farm management found that the sanitary conditions on the farm and inadequate management influenced the rate of infection of Cryptosporidium in dairy cows [36]. Farms with poor management and bad sanitary conditions present a high risk of Cryptosporidium and other gastrointestinal protozoan infections. In this study, risk factor analysis indicated that location was significantly associated with Cryptosporidium spp. infection. The risk of infection was higher in pet shops than in farms even though the former did not use for breeding, but only for selling snakes. However, our observation during sample collection found that some pet shops have many species of animals, and keep them at high densities in small cages. They also used contaminated equipment. The result is that pet shops tend to have a higher percentage of Cryptosporidium spp. infection than private farms.

Phylogenetic analysis of SSU rRNA gene fragments within the genus Cryptosporidium has proven to be a useful tool for both the systematic analysis of the presently recognized species and the possibility of definitive identification of new species or genotypes within this genus [4]. In this study, we identified 6 different Cryptosporidium species or genotypes in reptiles. These results confirmed that $C$. serpentis and $C$. parrum are the main species found in snakes.

A high proportion of Cryptosporidium species from mam- mals $(75.0 \%)$ was detected in this study consisting of $C$. parvum, C. muris, Cryptosporidium mouse genotype, and C. andersoni. However, these Cryptosporidium are non-pathogenic in snakes but potentially zoonotic. Cryptosporidiosis causes mucoid or hemorrhagic diarrhea, fever, lethargy, anorexia, and death especially in immunocompromised patients [11,37-39]. Additionally, C. muris is probably the zoonotic Cryptosporidium, which was reported in HIV patients in Perú, Thailand, Indonesia, France, and Kenya [40]. Recently, C. andersoni has been found in 21 diarrhea patients out of 232 outpatients in China, whereas Cryptosporidium hominis (the human genotype) was found only in 2 patients [41]. In 2015, C. andersoni was first reported in a captured lesser panda in China [42]. Therefore, the present identification of $C$. andersoni might have a public health impact. Additionally, Cryptosporidium has an environmentally resistant oocyst, which is a public health risk factor for handlers and owners, especially when they are children, elderly people, or immunocompromised patients. Consequently, feeding snakes with Cryptosporidium infected mice or any other prey could possibly transmit the pathogen to humans via feces, water, and contaminated equipment. Although a substantial study of Cryptosporidium transmission from reptiles to humans has not been reported yet, disinfection processes have been recommended as the best option for reducing the transmission risk by the application of 4-cholr-M-cresol, 5\% ammonium solution, or hydrogen peroxide-based disinfectants [14,21,32]. The presence of Cryptosporidium infection in snakes should not be ignored in snake collections because infection can be transmitted from animal to animal by the fecal-oral-route when animals are housed together. The lack of effective treatment for cryptosporidiosis almost always results in euthanasia of the infected snakes, which often leads to the loss of valuable animals in a collection [43]. Hyperimmune bovine colostrum (HBC) is recommended to combat clinical and subclinical C. serpentis infections in captive snakes [44].

In conclusion, applying a molecular method for the detection of the pathogen will probably prove the presence of the Cryptosporidium species or genotype, because it is difficult to identify oocysts of pathogenic C. serpentis or C. saurophilum from those of non-pathogenic Cryptosporidium species [45]. The study has shown that molecular techniques can separate different species and genotypes of Cryptosporidium. The sequencing of the PCR products revealed that C. parnum, C. serpentis, C. muris, C. mouse genotype, C. andersoni, and C. sauro- 
philum are different from each other. In addition, the PCRRFLP technique can differentiate various $C$. parrum genotypes (e.g., C. parrum human, C. parrum mouse, and C. parvum bovine genotypes) [45]. This study found a high percentage of non-pathogenic Cryptosporidium in snakes in Thailand. However, some species were zoonotic Cryptosporidium, which might have been ingested from prey and passed through intestinal tract of the snake.

Cryptosporidium oocysts from food items can cause the misidentification of cryptosporidiosis in snakes. In addition, paying more attention to cryptosporidiosis in snakes is required due to public health concerns. Moreover, the sanitary conditions associated with snake feeding should be improved along with avoiding the purchase of infected feeds. Thus, practicing good sanitation and hygiene, including at snake prey suppliers, should be considered, and these places tested for specific pathogens and to prevent the killing of snakes infected with non-pathogenic Cryptosporidium.

\section{ACKNOWLEDGMENTS}

This study was supported by a research grant from the Faculty of Veterinary Medicine, Kasetsart University, Thailand. Many thanks to the Kasetsart University Research and Development Institute (KURDI) for English editing of this manuscript.

\section{CONFLICT OF INTEREST}

The authors declare that there are no conflicts of interest.

\section{REFERENCES}

1. Fayer R. Cryptosporidium and Cryptosporidiosis. Boca Raton, Florida, USA. CRC Press. 1997, pp 1-251.

2. Navin TR, Juranek DD. Cryptosporidiosis: clinical, epidemiologic and parasitologic review. Rev Infect Dis 1984; 6: 313-327.

3. O'Donoghue PJ. Cryptosporidium and cryptosporidiosis in man and animals. Int J Parasitol 1995; 25: 139-195.

4. Xiao L, Ryan UM, Graczyk TK, Limor J, Li L, Kombert M, Junge R, Sulaiman IM, Zhou L, Arrowood MJ, Koudela B, Modrý D, Lall AA. Genetic diversity of Cryptosporidium spp. in captive reptiles. Appl Envion Microb 2004; 70: 891-899.

5. Plutzer J, Karanis P. Molecular identification of a Cryptosporidium saurophilum from corn snake (Elaphe guttata guttata). Parasitol Res 2007; 101: 1141-1145.

6. Pedraza-Díaz S, Ortega-Mora LM, Carrión BA, Navarro V, Gó-
mez-Bautista M. Molecular characterisation of Cryptosporidium isolates from pet reptiles. Vet Parasitol 2009; 160: 204 -210.

7. Ramirez NE, Ward LA, Sreevatsan S. A review of the biology and epidemiology of cryptosporidiosis in humans and animals. Microbes Infect 2004; 6: 773-785.

8. Rataj AV, Lindtner-Knific R, Vlahovic K, Mavri U, Dovc A. Parasites in pet reptiles. Acta Vet Scand 2011; 53: 33.

9. Rinaldi L, Capasso M, Mihalca AD, Cirillo R, Cringoli G, Caccio S. Prevalence and molecular identification of Cryptosporidium isolates from pet lizards and snakes in Italy. Parasite 2012; 19: 437440.

10. Graczyk TK, Cranfield MR. Assessment of the conventional detection of fecal Cryptosporidium serpentis oocysts in subclinically infected captive snakes. Vet Res 1996; 27: 185-192.

11. Xiao L. Molecular epidemiology of cryptosporidiosis: an update. Exp Parasitol 2010; 124: 80-89.

12. Morgan UM, Xiao L, Fayer R, Graczyk TK, Lal AA, Deplazes P, Thompson RC. Phylogenetic analysis of Cryptosporidium isolates from captive reptiles using $18 \mathrm{~S}$ rDNA sequence data and random amplified polymorphic DNA analysis. J Parasitol 1999; 85: 525-530.

13. Richter B, Nedorost N, Maderner A, Weissenböck H. Detection of Cryptosporidium species in feces or gastric contents from snakes and lizards as determined by polymerase chain reaction analysis and partial sequencing of the 18 S ribosomal RNA gene. J Vet Diagn Invest 2011; 23: 430-435.

14. Díaz P, Rota S, Marchesi B, López C, Panadero R, Fernández G, Díez-Baños P, Morrondo, P, Poglayen G. Cryptosporidium in pet snakes from Italy: molecular characterization and zoonotic implications. Vet Parasitol 2013; 197: 68-73.

15. Inpankaew T, Jiyipong T, Pinyopanuwat N, Chimnoi W, Thompson RC, Jittapalapong S. Prevalence and genotyping of Cryptosporidium spp. from dairy cow fecal samples in western Thailand. Southeast Asian J Trop Med Public Health 2010; 41: 771-775.

16. Bronsdon MA. Rapid dimethyl sulfoxide-modified acid-fast stain of Cryptosporidium oocysts in stool specimens. J Clin Microbiol 1984; 19: 952-953.

17. Xiao L, Escalante L, Yang C, Sulaiman I, Escalante AA, Montali RJ, Fayer R, Lal AA. Phylogenetic analysis of Cryptosporidium parasites based on the small-subunit rRNA gene locus. Appl Environ Microbiol 1999; 65: 1578-1583.

18. Goujon M, McWilliam H, Li W, Valentin F, Squizzato S, Paern J, Lopez R. A new bioinformatics analysis tools framework at EMBL-EBI. Nucleic Acids Res 2010; 38: 695-699.

19. Sievers F, Wilm A, Dineen D, Gibson TJ, Karplus K, Li W, Lopez R, McWilliam H, Remmert M, Söding J, Thompson JD, Higgins DG. Fast, scalable generation of high-quality protein multiple sequence alignments using Clustal Omega. Mol Syst Biol 2011; 7: 539.

20. Tamura K, Peterson D, Peterson N, Stecher G, Nei M, Kumar S. MEGA5: molecular evolutionary genetics analysis using maximum likelihood, evolutionary distance, and maximum parsimony methods. Mol Biol Evol 2011; 28: 2731-2739. 
21. Fayer R. General biology. In Fayer R, Xiao L eds, Cryptosporidium and Cryptosporidiosis. 2nd ed. Boca Raton, Florida. CRC Press. 2008, pp 1-42.

22. Brownstein DG, Strandberg JD, Montali RJ, Bush M, Fortner J. Cryptosporidium in snakes with hypertrophic gastritis. Vet Pathol 1977; 24: 606-617.

23. Guo PF, Chen TT, Tsaihong JC, Ho GD, Cheng PC, Tseng YC, Peng SY. Prevalence and species identification of Cryptosporidium from fecal sample of horses in Taiwan. Southeast Asian J Trop Med Public Health 2014; 45: 6-12.

24. Kurniawan A, Dwintasari SW, Soetomenggolo HA, Wanandi SI. Detection of Cryptosporidium sp. infection by PCR and modified acid fast staining from potassium dichromate preserved stool. Med J Indones 2009; 18: 147-152.

25. Coupe S, Sarfati C, Hamane S, Derouin F. Detection of Cryptosporidium and identification to the species level by nested PCR and restriction fragment length polymorphism. J Clin Microbiol 2005; 43: 1017-1023.

26. Fathy MM, Abdelrazek NM, Hassan FA, El-badry AA. Molecular copro-prevalence of Cryptosporidium in Egyptian children and evaluation of three diagnostic methods. Indian Pediatr 2014; 51: 727-729.

27. El-Hamshary EM, El-Sayed HF, Hussein EM, Rayan HZ. Comparison of polymerase chain reaction immunochromatographic assay and staining techniques in diagnosis of cryptosporidiosis. Parasitol United J 2008; 1: 77-86.

28. Paul S, Chandra D, Tewari AK, Banerjee PS, Ray DD, Boral R, Rao JR. Comparative evaluation and economic assessment of coprological diagnostic methods and PCR for detection of Cryptosporidium spp. in bovines. Vet Parasitol 2009; 164: 291-295.

29. Omoruyi BE, Nwodo UU, Udem CS, Okonkwo FO. Comparative diagnostic techniques for Cryptosporidium infection. Molecules 2014; 19: 2674-2683.

30. Karim MR, Yu F, Li J, Li J, Zhang L, Wang R, Rume FI, Jian F, Zhang S, Ning C. First molecular characterization of enteric protozoa and the human pathogenic microsporidian, Enterocytozoon bieneusi, in captive snakes in China. Parasitol Res 2014; 113: 3041-3048.

31. Koudela B, Modrý D. New species of Cryptosporidium (Apicomplexa: Cryptosporidiidae) from lizards. Folia Parasitol 1998; 45: 93-100.

32. Pasmans F, Blahak S, Martel A, Pantchev N. Introducing reptiles into a captive collection: the role of the veterinarian. Vet J 2008; 175: 53-68.

33. Graczyk TK, Fayer R, Cranfield MR. Cryptosporidium parvum is not transmissible to fish, amphibians, or reptiles. J Parasitol 1996; 82: 748-751.

34. Graczyk TK, Cranfield, MR. Experimental transmission of Cryptosporidium oocyst isolates from mammals, birds and reptiles to captive snakes. Vet Res 1998; 29: 187-195.

35. Lindsay DS, Upton SJ, Owens DS, Morgan UM, Mead JR, Blagburn BL. Cryptosporidium andersoni n. sp. (Apicomplexa: Cryptosporiidae) from cattle, Bos taurus. J Eukaryot Microbiol 2000; 47: 91-95.

36. Couto MCM, Lima MF, Pires MS, Bomfim TCB. The occurrence of Cryptosporidium parrum in dairy calves and the influence of management practices. J Dairy Vet Anim Res 2015; 2: 00031. DOI: 10.15406/jdvar.2015.02.00031.

37. Katsumata T, Hosea D, Ranuh IG, Uga S, Yanagi T, Kohno S. Short report: possible Cryptosporidium muris infection in humans. Am J Trop Med Hyg 2000; 62: 70-72.

38. Gatei W, Suputtamongkol Y, Waywa D, Ashford RW, Bailey JW, Greensill J, Beeching NJ, Hart CA. Zoonotic species of Cryptosporidium are as prevalent as the anthroponotic in HIV-infected patients in Thailand. Ann Trop Med Parasitol 2002; 96: 797-802.

39. Lassen B, Ståhl M, Enemark HL. Cryptosporidiosis - an occupational risk and a disregarded disease in Estonia. Acta Vet Scand 2014; 56: 36.

40. Palmer CJ, Xiao L, Terashima A, Guerra H, Gotuzzo E, Saldías G, Bonilla JA, Zhou L, Lindquist A, Upton SJ. Cryptosporidium muris, a rodent pathogen, recovered from a human in Perú. Emerg Infect Dis 2003; 9: 1174-1176.

41. Jiang Y, Ren J, Yuan Z, Liu A, Zhao H, Liu H, Chu L, Pan W, Cao J, Lin Y, Shen Y. Cryptosporidium andersoni as a novel predominant Cryptosporidium species in outpatients with diarrhea in Jiangsu Province China. BMC Infect Dis 2014; 14: 555.

42. Wang T, Chen Z, Yu H, Xie Y, Gu X, Lai W, Peng X, Yong G. Prevalence of Cryptosporidium infection in captive lesser panda (Ailurus fulgens) in China. Parasitol Res 2015; 114: 773-776.

43. Carmel BP, Groves V. Chronic cryptosporidiosis in Australian elapid snakes: control of an outbreak in captive colony. Aust Vet J 1993; 70: 293-295.

44. Graczyk TK, Cranfield MR, Helmer P, Fayer R, Bostwick EF. Therapeutic efficacy of hyperimmune bovine colostrum treatment against clinical and subclinical Cryptosporidium serpentis infections in captive snakes. Vet Parasitol 1998; 74: 123-132.

45. Xiao L, Morgan UM, Limor J, Escalante A, Arrowood M, Shulaw W, Thompson RCA, Fayer R, Lal AA. Genetic diversity within Cryptosporidium parvum and related Cryptosporidium species. Appl Envir Microbiol 1999; 65: 3386-3391. 